\title{
The Application of Engineering Cognitive Museum in Engineering Training Teaching
}

\author{
Peng'an Qian \\ Engineering Training Center \\ Hefei University of Technology \\ Anhui, Hefei, 230009
}

\begin{abstract}
Engineering Cognitive Museum of HeFei University of Technology is a non-profit education base which displays people the connotation of engineering in various forms like real objects, models, display boards, pictures and diagrams. In the course of "Engineering Training", through analyzing and summarizing the content and teaching of exhibition halls, the author believes that the museum can serve as an ideal experimental platform for cognitive training of engineering and also as a practice platform for students to perceive "engineering". What's more, we will conduct exploration constantly to enhance its teaching function and exert its educational and teaching functions.
\end{abstract}

Keywords-engineering cognition, engineering training, museum, teaching

\section{INTRODUCTION}

The guiding ideology of the "Engineering Training" course in colleges and universities is to cultivate students' comprehensive engineering practice ability and engineering innovation capability, establish engineering awareness and cultivate engineering quality, and establish the idea of largescale engineering. However, due to the complexity of modern industrial systems, it is difficult for students to fully and practically access various advanced industrial production processes in schools. In order to enable students to contact and understand advanced industrial technologies and production methods in the course of the "Engineering Training", Hefei University of Technology has added the teaching content of engineering cognitive training in modern industrial products and modern industrial systems while carrying out basic engineering training [1].

The fundamental goal of engineering cognitive training is to expand students' scope of industrial knowledge, improve their comprehensive engineering quality, and cultivate students' engineering practice and innovation abilities. Focusing on this goal, we establish a sound engineering cognitive education platform, enrich the teaching content, and improve the engineering cognitive education method and teaching force. Under the circumstances, students can understand the principles and structures of typical industrial products, the operation of the core industrial system, and the development of the relative technology or product as well as technology frontier. Through training, students' industrial vision is fully extended to the entire industrial background. Students form the thinking mode of large-scale engineering and system engineering. At the same time, a systemic platform is built for students to learn open thinking and engineering in their follow-up study of theoretical and practical courses.

The engineering of Museums is a non-profit education base wholly owned by Hefei University of Technology, and invested by the Ministry of Education's base funds for management. As the National Experimental Demonstration Center, Hefei University of Technology Industrial Training Center was prepared as a construction unit in December 2012. It was not until 2012 that the museum officially opened its doors to the whole society for free. Covering an area of approximately 6,600 square meters, the museum is composed of indoor exhibition hall and outdoor one; according to the construction process, the indoor exhibition hall has gone through first stage and second stage construction. The first phase of the project consists of eight halls: the Preface Hall, the Projection Hall, the Electrical Engineering Hall, the Materials Engineering Hall, the Automotive Engineering Hall, the Mechanical Engineering Hall, the Biological Specimen Hall, and the Electronic Information Engineering Hall, and each of them displays the connotation of "project" to visitors in the form of physical objects, models, exhibition boards, pictures, charts, sculptures, landscapes, and videos.

Since 2011, the Engineering Training Course team has opened the museum for engineering training course Class $\mathrm{D}$ majors and freshmen [2]. Engineering Training Course D is a basic practice course for non-engineering majors (including mathematics, information and computing science, English, etc.) whose task is to get started with basic practice so that students can maintain the necessary engineering concepts and awareness to increase sensibility for the related courses. Having been researching on teaching in the museum over seven years, the author believes that the museum can serve as a good teaching platform for engineering training courses. This platform can help students to understand the industrial system from the very beginning, establish the overall concept of engineering technology and figure out the positions of professional professions in the entire industrial production chain and their links with other professions; it will provide students with an open-minded, experimental enlightenment education laboratory for the study of theoretical and practical courses.

In this article, we will introduce, analyze and summarize the teaching application of Preface Hall, Electrical Engineering Hall, Materials Engineering Hall, Automotive 
Engineering Hall, Electronic Information Engineering Hall, and Biological Specimen Hall in the museum fist stage construction, in order to provide a reference for engineering training education in higher universities and colleges.

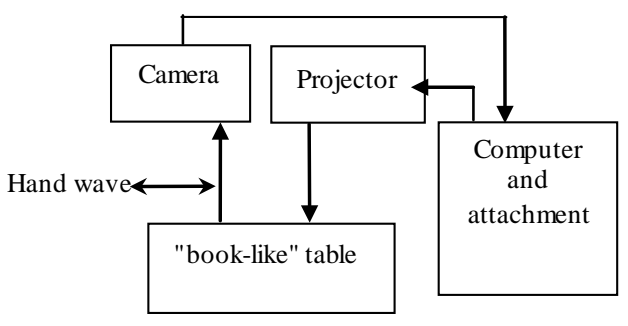

Fig. 1. Composition of Virtual Open Book

\section{Teaching Application of the Museums}

\section{A. Preface Hall}

The "virtual open book" in the Display Hall works as Fig. 1 shows.

Its working principle is like this: the camera transmits the "hand-wave" book-turning instructions from the visitors to the computer. The information processing and management software within the computer will identify and recognize the instructions, and the projector will project the contents of the front page (or the rear page) of the computer document onto the "book-like" table to realize the "book-turning".

The device uses information acquisition technology, information processing, computer control and multimedia display to show the contents of each exhibition hall and the connotation of the "engineering" to visitors, so that visitors can have a thorough understanding of the museum construction and "engineering".

\section{B. Electrical Engineering Hall}

The Electrical Engineering Hall introduced electric machines, power systems, and electrical appliances which are all about electricity. How does "Electricity" benefit people? According to the principle of energy conversion, electrical energy can be converted into kinetic energy, mechanical energy, and thermal energy. This needs the aid of relevant electrical equipment like "electric machine", cables, electrical appliances, etc.

Electricity awareness, research, experiment, and engineering application will be illustrated by pictures. With the Siemens R1619/750 motor, the introduction of the time lag between theoretical experimental study and the realization of the project shows the practical significance of the engineering.

Focusing on the power system, we mainly elaborate power generation, transmission, transformation, distribution, and utilization in power industry. In the transmission of electricity, energy consumption needs to be considered. Generally, highvoltage, overhead, bare metal conductors are used for transmission, which requires boost (or buck) with the help of a "power transformer." Furthermore, safety (insulation) should be carefully considered in the transmission of electricity. What's more, various cables are needed in cities, rural areas, factories, and mechanical systems. Here we show students the cable structure with a variety of cable segments placed in the windows.

The display of electrical equipment are aimed at devices that are closely related to learning and life, such as resistors (potentiometers), knife switches, small transformers, capacitors, and inductors, measuring instruments (ohmmeters, voltages, ammeters) hand generator system used in school laboratories. At the same time, students can watch the equipment of power into the home: distribution box, power meter, voltage switch cabinet and so on.

\section{Materials Engineering Hall}

In the Materials Engineering Hall, such stages as people's understanding, research and application of materials are briefly introduced. The stages can be recognized as the primary stage when people used natural materials, the stage of simply using fire to make materials (including Neolithic Age, Bronze Age and Iron Age), the modern stage of the synthesis of materials supported by physical and chemical principles (synthetic polymer materials and metal and ceramic materials constitute the three pillars of modern materials), as well as the stage of compounding and intellectualizing materials.

We will mainly adopt pictures, description and interactions to enable visitors to experience and understand the properties and charming of new materials. Thermochromic liquid crystal/liquid crystal glass is transparent when energized but opaque when no electricity is applied. Ultraviolet-activated material can emit red, yellow, blue, green and other visible light under the irradiation of ultraviolet light. The light storage material, made of rare earth, can emit green Fluorescence if being exposed to light for a while. The magnetic particle whose size is less than 10 nanometers, when dissolved in the solution, will result in nano magnetic fluid which will form a nail bed effect under the influence of a magnetic field. That the material can drink water means it absorbs one thousand times the amount of the water it can carry. Cut endurable gloves are specially made from high-strength, high-density polyethylene cloth. Stone paper which uses stone as raw material is a kind of paper between plastic and paper.

\section{Automotive Engineering Hall}

In Automotive Engineering Hall, the visit will center on four parts that compose an automobile, namely chassis, engine, body and electronic equipment.

The chassis, comprised of consists of powertrain, travelling system, steering system, and braking system, is the base body that supports and accommodates the components of the automobile. It receives the power of the engine and generates relative movement between the vehicle and the ground to ensure normal driving. Here, the "Great Wall" pickup truck [3] is used as an example. Students can see the carburetor, engine, crankshaft connecting rod, clutch, gearbox and transmission shaft, fuel tank, front and rear axles and the hub. They will get to know the structure of the car and its 
operation. In short, how the car runs is how to obtain kinetic energy and drive on the road through mechanical transmission. In fact, what is shown is an "electric pickup truck", because its original fuel engine has been replaced by an electric motor (taking into account indoor use, safety of demonstrations, etc.). When turning on the power, students can witness the running of its rear wheels, the power transmission process, speed changing and direction control, and so on.

As for the working principle of the fuel engine, students can recall the knowledge acquired in high school, that is, the four strokes of the fuel engine work. Taking the Santana sedan as an example, through the "panel" electronic simulation demonstration, we expound the air compression, ignition, work, exhaust, and light simulation under various load conditions. Here, students can also well understand the electronic injection system, fuel supply system, mechanical gasoline injection system, ignition system, cooling system, lubrication system, hydraulic clutches and electromechanical gasoline pump, transmission running, and hydraulic brakes of automobiles. And many automotive parts are helpful for students to understand automatic / manual reducer, airbags, damping springs and other components.

The Santana 2000GSI simulation circuit training platform is used to briefly introduce the work of electrical and electronic equipment in automobiles, including lighting, ignition system, engine EFI system for, sound system, and engine cooling system. However, the carrying capacity of drivers, passengers, and cargo is preferred to be left for students to figure out.

\section{E. Electronic Information Engineering Hall}

The Electronic Information Engineering Hall focuses on information acquisition, processing, storage, communication, display and other technologies and related devices, involving integrated circuits, communication technologies, computer technologies, sensing technologies, and Internet of Things technologies.

By learning in this hall, students from different majors will be aware of the similarities and differences between integrated circuits and discrete electronic components, and acquire a general knowledge that integrated circuits can form a variety of circuits, realize storage and logic operations, and may form a computer CPU. The relevant communication equipment and devices placed in the display window, such as the dispatcher, telephones, pagers, and cellular phone, enable students to understand the brief history of the development of telegraphy, cable (and wireless) communication. As for computer, students are instructed to review history by the display of calculator, microcontroller, printer, cash register, computer motherboards, etc. In particular, a hand computer [4] will be introduced about its elementary arithmetic, working principle of square, cube, square root and extraction of cube root.

In addition, a brief description is given of the shown receiving and display devices: radios, televisions, sounders and projection devices, especially phonographs (which may only be seen in some TV movies). Students are allowed to have close contact and experience with electronic oscilloscopes, mimeograph equipment, and sensing and testing instruments.

In order to enhance students' interest, they also use simple pull or press force test devices [2] during the explanation. With the device, students can compare and see who is stronger. The device is shown in Fig. 2. The component 1 is pedal, 2 strain gauge pull pressure sensor, 3 power and instrument, 4 pull rod, and 5 pull handle. The operator steps on the pedals with both feet and pulls up the handle with both hands. The device shows the value of the pulling force.

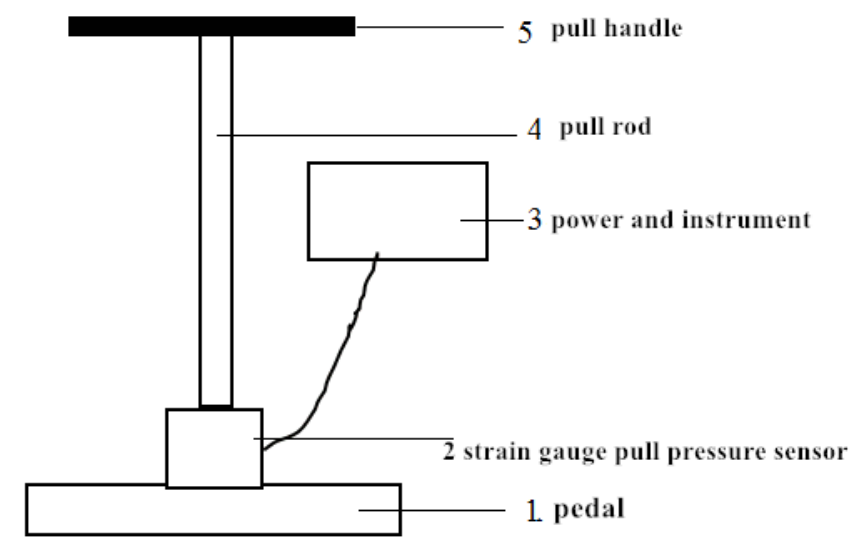

Fig. 2. Pull or press force test device

As for the test principle, it is briefly explained. The tension of the hands is transmitted to the sensor through the pull rod, and the resistance strain gauge attached to the sensor's elastic body (mechanical sensitive body) changes due to the deformation. The corresponding circuit measures the variation of the resistance value. Finally, the strength will be displayed through data acquisition, and processing. For cognitive learning, it is mainly for students to understand the design, processing, and production process, encourage them to design similar devices and complete related design tasks.

\section{F. Biological Specimen Hall}

In order to raise students' autonomous learning enthusiasm, we arranged students to visit the Biological Specimen Hall freely. The exhibition hall is formed through practice by students of our biomedical engineering and other specialties under the guidance of teachers. It has become an important base for advocating life science, cultivating students' biological interests, and scientific innovation and quality education for undergraduates, and also one of the characteristics of school teaching evaluation.

In the hall, there are biological specimens of monkeys and poultry, specimens of various plants and insects, and the plants include treasured specimens such as ginkgo biloba and Taxus chinensis. As for animals, there are large specimens like young sharks and lobsters, etc., and small ones like paramecium, the single-celled organism that cannot be seen by the naked eye. Through the visits, the students were very interested in gaining more knowledge while broadening their horizons. 


\section{CONCLUSION}

More than seven years of teaching proves that through the experience and learning in museums, students have deepened their understanding of the basic concepts and basic knowledge of engineering materials and machinery manufacturing. Their comprehensive quality (including engineering quality) has been improved. And they begin to build responsibilities, safety, innovation, groups, competition and other engineering awareness. In the entire teaching process, the atmosphere was active. Students were diligent in observing, learning, thinking, and exploring; they have recognized the systematic nature, complexity, and completeness of the "engineering” itself.

It is also necessary to enrich, improve and complete teaching content and teaching methods, and actively encourage and mobilize more people to participate in related teaching activities to better improve and enhance the teaching efficacy of the museums of engineering. In the future teaching, we will introduce more contents to the exhibition halls of the second phase of the museum, which will cover the exhibition halls of resources and environment, transportation, civil engineering and water conservancy, biology and food, chemical engineering, aerospace, boats and ships, and integrated science and technology engineering. With all these effort, we look forward that the museums can play a better role in the education and teaching of engineering training in colleges and universities

The author would like to express gratitude to those who have instructed, supported, and assisted in teaching, and also Engineering Training and Teaching Group of Hefei University of Technology and the Engineering Cognitive Museum for their support and assistance.

\section{REFERENCES}

[1] Xi Yun. Exploration of Engineering Cognitive Training Teaching. The 9th Academic Annual Meeting of East China College of Engineering Training and Teaching(collected papers).2011.11,60-61

[2] Qian Peng'an. The Project Design of Engineering Cognitive Interactive Teaching. The 9th Academic Annual Meeting of East China College of Engineering Training and Teaching(collected papers). 2011.11,105-106

[3] The Historical Imprint of "Electromechanical World". http://epaper.anhuinews.com/files/ahrb/20120406/index.htm

[4] Engineering Cognitive Museum of HeFei University of Technology opens to the outside world.

http://news.mediaxinan.com/hefei/2012/0319/1129323.shtml 